\title{
Percutaneous intervention for diffuse pulmonary arteriovenous malformations by occlusion of large lobar pulmonary arteries
}

\section{Adèle Greyling" and Lungile Pepeta*}

"Department of Paediatrics and Child Health, Division of Paediatric Cardiology, Dora Nginza Hospital, Port Elizabeth, South Africa \#Faculty of Health Sciences, Nelson Mandela University, Port Elizabeth, South Africa

Address for correspondence:

Dr A. Greyling

Division of Paediatric Cardiology

Dora Nginza Hospital

Spondo Street

Port Elizabeth

6057

South Africa

Email:

Adelegreyling |@gmail.com

\section{BACKGROUND}

Pulmonary arteriovenous malformations (PAVMs) are abnormal communications between pulmonary veins and arteries. ${ }^{(1)}$ They are uncommon, but they should be considered after other causes of cyanosis and clubbing (chronic lung disease, cyanotic congenital heart disease and chronic liver disease) have been excluded. ${ }^{(2-5)}$

Historically, the treatment of PAVMs is selective angiography and embolisation of the distal feeding arteries with coils or detachable balloons; or surgical resection of affected lobe/s. Detachable balloons are no longer available for clinical use. Amplatzer $^{\circledR}$ vascular plugs have been shown to be safe in the management of simple, focal PAVMs. ${ }^{(6)}$ Diffuse PAVMs are more challenging to treat.

Diffuse PAVMs that have been managed by occlusion of the right and left lower lobar pulmonary arteries will be reported.

\section{CASE REPORT}

An 8-year-old female was referred by her dentist with clubbing and cyanosis. She had a year-long history of deteriorating exercise tolerance. On examination she was tachypnoeic, with

\section{ABSTRACT}

We present a case of an 8-year-old girl with bilateral, diffuse, lower lobe pulmonary arteriovenous malformations (PAVMs). These were initially treated by selective embolisation of the feeder arteries with coils and vascular plugs. Due to unsatisfactory results (persistent cyanosis and diffuse residual PAVMs), prolonged procedure time, high contrast dose and the fact that she was declined surgical resection by cardiothoracic surgery as she was perceived to be a high anaesthetic risk and surgical resection was presumed to be complex; a staged approach for occlusion of the left and right lower lobar pulmonary arteries with large vascular plugs was chosen. SAHeart 2018;15:134-137

severe wasting, cyanosis (with oxygen saturations of $68 \%$ in room air) and digital clubbing. There were no cutaneous telangiectasias noted. Special investigations revealed polycythaemia (haemoglobin $=22.8 \mathrm{~g} / \mathrm{dl}$ ) and thrombocytopaenia (platelet count $=97 \times 109 / \mathrm{L})$. The Chest $\mathrm{x}$-ray $(\mathrm{CXR})$ showed nodular lesions in both lower lobes with increased vascular markings but no cardiomegaly. Electrocardiogram (ECG) was normal and there was no intracardiac shunting seen on echocardiography. Contrast echocardiogram with agitated saline was positive, thus supporting the diagnosis of pulmonary arteriovenous malformations. Cardiac catheterisation with main pulmonary angiography showed diffuse PAVMs involving both lower lobes.

Selective left and right angiography was performed through a 5.2 French Cordis $^{\circledR}$ Multi-Purpose I catheter to identify the feeder vessels. Four feeder arteries in the right lower lobe were occluded by delivering 4 Cook $^{\circledR}$ coils ( I coil $=0.035$ inch $\times 1 \mathrm{~cm} \times 3 \mathrm{~mm} ; 2$ coils, 0.035 inch $\times 3 \mathrm{~cm} \times 7 \mathrm{~mm}$ and I coil, 0.0 .35 inch $\times 3 \mathrm{~cm} \times 4 \mathrm{~mm}$ ), through a $4 \mathrm{~F}$ delivery system. The anchor technique was applied by way of occluding a small collateral branch of the feeder artery upstream to the PAVM which would then act as a scaffold facilitating the placement of other coils. This lowers the risk of coil embolisation.

In our case, however, the outcome was suboptimal due to the diffused nature of disease (Figure I). 
A week later, selective angiography and embolisation of feeder arteries in the left lower lobe with 3 Amplatzer $^{\circledR}$ vascular plugs type IV (4mm, 6mm and $8 \mathrm{~mm})$, I vascular plug type I $(8 \mathrm{~mm})$ and I vascular plug type ||$(8 \mathrm{~mm})$ was performed (Figures 2A and $2 \mathrm{~B})$.

Arterial oxygen saturations improved marginally from 68\% $74 \%$ as a result of residual PAVMs in the right lower lobe. Due to prolonged screening time, contrast dose, the diffuse nature of disease, patient's clinical condition, sub-optimal improvement in saturations and the fact that the patient was denied surgical resection, we elected to occlude the right lower lobar pulmonary artery using an $18 \mathrm{~mm}$ Amplatzer ${ }^{\circledR}$ vascular plug type ॥ (Figure 3). Saturations (sPO2) improved to 94\%. She developed a right-sided pleural effusion post procedure which resolved spontaneously. On I-month follow up, she was thriving, with saturations of $99 \%$ on room air.

Thirteen months later, she presented with disease recurrence with cyanosis (sPO2 87\%) and exercise intolerance. Pulmonary angiography confirmed recurrence of disease on the left lower lobe. Occlusion of the left lower lobar pulmonary artery using an $18 \mathrm{~mm}$ Amplatzer $®$ vascular plug type I| was performed (Figure 4).

The sPO2 improved to $97 \%$ immediately following occlusion and, to date, she remains asymptomatic with sPO2 >95\% in room air with no signs of pulmonary hypertension clinically or on echocardiography.

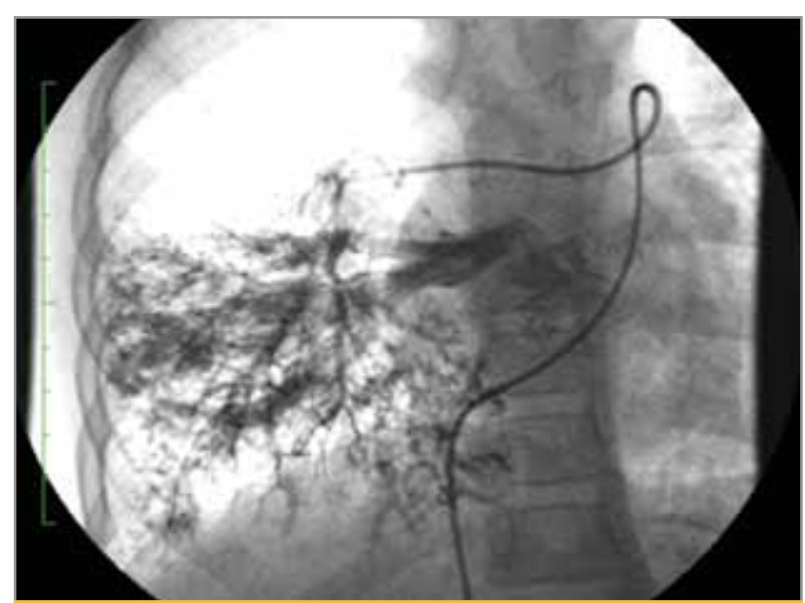

FICURE I: Selective right lower pulmonary angiography demonstrating suboptimal results with residual pulmonary arteriovenous malformations after selective embolisation of feeding arteries with Cook $^{\circledR}$ Coils.

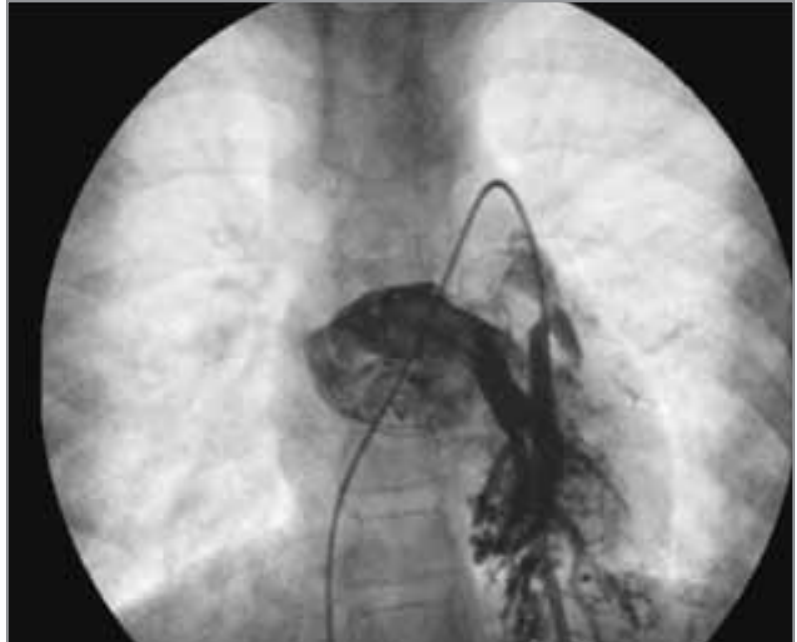

FIGURE 2A: Selective left lower pulmonary angiography demonstrating diffuse pulmonary arteriovenous malformations.

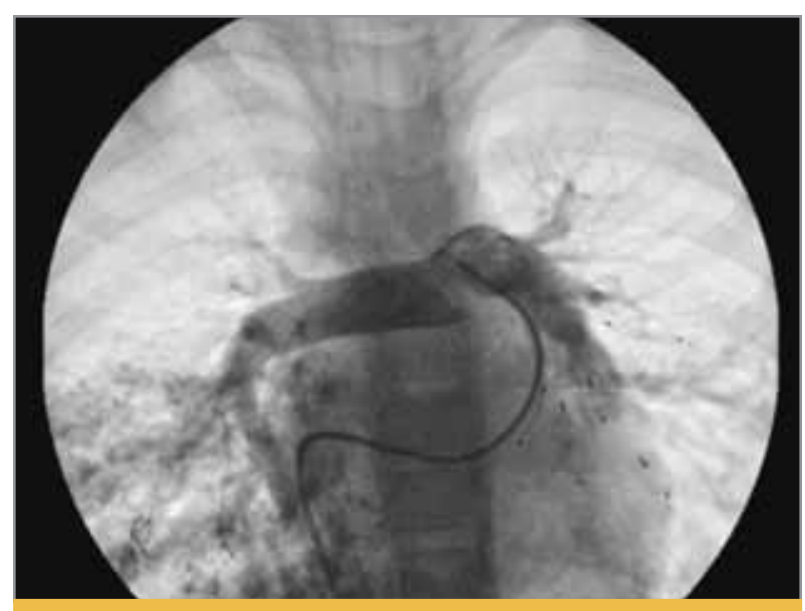

FIGURE 2B: Pulmonary angiogram demonstrating suboptimal coil embolisation of the right lower lung feeder arteries and optimal occlusion of the left lower lung feeder arteries with Amplatzer ${ }^{\circledR}$ vascular plugs type II.

\section{DISCUSSION}

PAVMs affect 2 - 3 per 100000 population and may be associated with hereditary haemorrhagic telangiectasia $(\mathrm{HHT}){ }^{(7,8)}$ This congenital, autosomal dominant disease includes arteriovenous malformations in several organs including pulmonary, cerebrovascular, hepatic system, nasal and gastrointestinal mucosa. PAVMs do not resolve spontaneously. Most increase in size, with accelerated growth in puberty, pregnancy and pulmonary arterial hypertension. Many patients remain asymptomatic, however, in about 30\%, PAVMs may result in right to left shunting, leading to shortness of breath, hypoxia, cyanosis, decreased exercise tolerance, high output heart failure, and paradoxical emboli and its complications including cerebral 


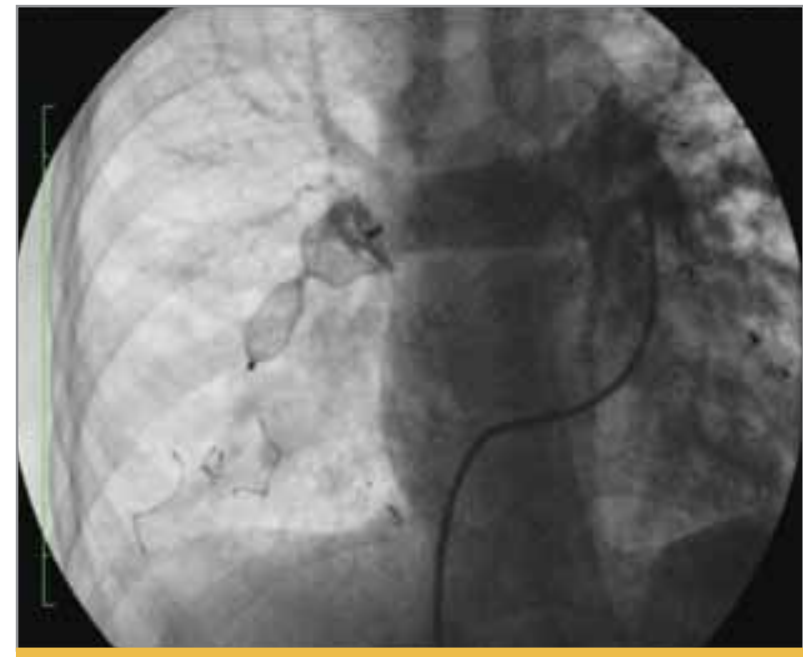

FIGURE 3: Pulmonary angiogram showing adequate right lower lobe arterial occlusion using an Amplatzer vascular plug type II with no residual pulmonary arteriovenous malformation flow seen.

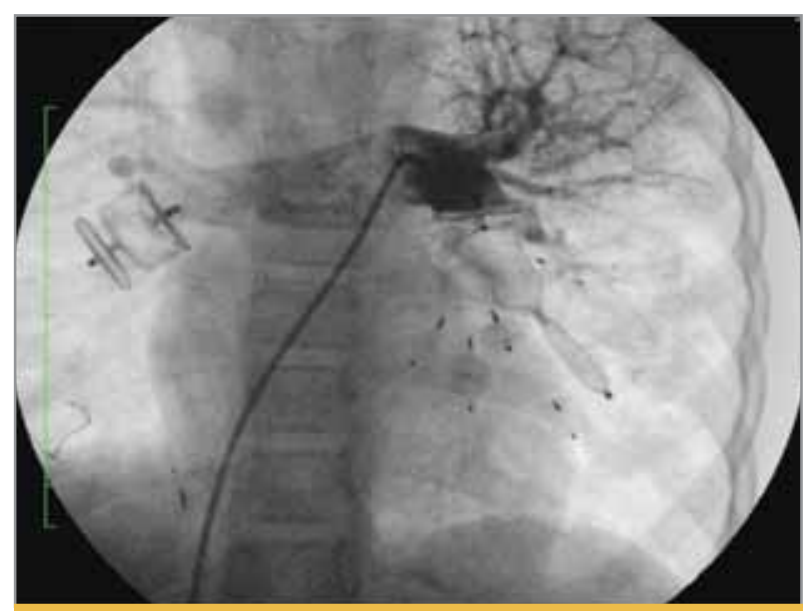

FIGURE 4: Pulmonary angiogram demonstrating complete resolution of pulmonary arteriovenous malformations after embolisation of the left lower pulmonary artery.

embolism, infarcts or brain abscesses. ${ }^{(9)}$ In addition, although rare outside of pregnancy, pulmonary arteriovenous malformations may bleed and present with haemoptysis or haemothorax. Even rarer, is the symptomatic presentation of a newborn infant with heart failure. ${ }^{(10)}$

Various modalities may be used in the diagnosis of PAVMs including CXR, pulmonary function tests, transthoracic contrast echocardiography, CT angiography, MRI angiography or radionucleotide lung perfusion scanning. CT scan remains the gold standard with the advantage of assisting in pre-procedural planning. (II)
The rationale for treatment is directed at symptomatic relief and reduction of morbidity and mortality by reducing or eliminating hypoxemia, right heart failure, haemorrhage and cerebrovascular accidents and abscesses. ${ }^{(2-5)}$

Regarding planning and management of PAVMs, they are classified into simple, complex and diffuse lesions. Simple (focal) PAVMs (75\%) have a single feeder artery leading to a single draining pulmonary vein. Complex PAVMs (20\%) have multiple feeder arteries and multiple draining pulmonary veins and diffuse PAVMs (5\%) having a rare combination of simple and complex PAVMs. ${ }^{(12)}$

Endovascular embolisation of pulmonary arteriovenous malformations has been shown to be safe and effective in simple PAVMs, even in the newborn period. ${ }^{(10)}$ The aim is to identify and occlude the feeder arteries. Our patient had diffuse disease type, affecting both lower lobes and that created a challenge in selectively occluding the lesions. Surgical management by either lobectomy, segmental wedge resection, vascular ligation or pneumonectomy, even though more invasive, may be the only definitive therapy in complex and diffuse cases. ${ }^{(13)}$

Surgical resection of the PAVMs in this patient was declined by a cardiothoracic surgeon due to perceived high anaesthetic and operative risks. The decision was then made to perform a staged percutaneous occlusion of the left and right lower lobar pulmonary arteries with large vascular plugs.

Possible immediate complications of percutaneous occlusion of PAVMs include device migration, stroke, pulmonary infarctions and haemoptysis. Mid- to long-term complications are pulmonary hypertension and haemoptysis and are due to reperfusion of the PAVMs, either through the coils/plugs, or due to the development of collaterals from the systemic bronchial and/or non-bronchial arteries to the PAVM. ${ }^{(14)}$ So far, this has not been the case in our patient.

Patients treated for PAVMs require follow up at I month, I year and every 5 years after embolisation to detect disease recurrence and prevent complications from paradoxical emboli. ${ }^{(15)}$

\section{CONCLUSION}

Percutaneous treatment of diffuse pulmonary arteriovenous malformations using coils and vascular plugs is possible. We present a case of diffuse PAVMs treated by percutaneous isolation of large lobar pulmonary artery vessels with only minor complications. 


\section{FINANCIAL SUPPORT}

This research received no specific grant from any funding agency, commercial or not-for-profit sectors.

\section{ETHICAL STANDARDS}

The authors assert that all procedures contributing to this work complies with the ethical standards of the relevant national guidelines on human experimentation (National Health Research Ethics Council of South Africa) and with the Helsinki Declaration of 1975, as revised in 2008, and has been approved by the institutional Chief Executive Officer of Dora Nginza Hospital, Port Elizabeth.

\section{Conflict of interest: none declared.}

\section{REFERENCES}

I. Churton, T. Multiple aneurysms of the pulmonary artery. Br Med J 1897; I:1223.

2. Swanson KL, Prakash UB, Stanson AW. Pulmonary arteriovenous fistulas: Mayo Clinic experience, 1982 - 1997. Mayo Clin Proc 1999;74:67I-680.

3. Dines DE, Arms RA, Bernatz PE, et al. Pulmonary arteriovenous fistulas. Mayo Clin Proc 1974:49:460-465.

4. Sluiter-Eringa $H$, Orie NG, Sluiter HJ. Pulmonary arteriovenous fistula. Diagnosis and prognosis in non-complainant patients. Am Rev Respir Dis 1969;100:177-188.

5. Gomes MR, Bernatz PE, Dines DE. Pulmonary arteriovenous fistulas. Ann Thorac Surg 1969;7:582-593.

6. Abdel Aal et al. Occlusion time for Amplatzer vascular plug in management of pulmonary ateriovenous malfomations. AJR 2009;793-799.

7. Gossage JR, Kanj G. Pulmonary arteriovenous malformations: A state of the art review. Am J Re- spir Crit Care Med 1998;|58:643-66|.

8. Kannan BR, Anil SR, Haridas KK, et al. Bioptome-assisted coil closure of large pulmonary arteriovenous malformations. J Vasc Interv Radiol. 2006; 17(1):|47-151.

9. Shovlin CL, Letarte M. Hereditary haemorrhagic telangiectasia and pulmonary arteriovenous malformations: Issues in clinical management and review of pathogenic mechanisms. Thor 1999;54:714-729.

10. Devanagondi R, Tapio JB, Grifka RG. Transcatheter occlusion of large pulmonary arteriovenous malformations using multiple devices in a neonate. Catheter Cardiovasc Interv. 20 15:85(3):430-4.

II. Remy J, Remy-Jardin M, Giraud F, et al. Angioarchitecture of pulmonary arteriovenous malformations: Clinical utility of three-dimensional helical CT. Radiology 1994; 191:657-64. 10.1 148/radiology. 191.3.8184042.

12. Nagre SW, Bhosle KN, Bendre S Vignesh R. (2017) Surgical management of medium to large size pulmonary AV malformations: A Case Series. J Clin Respir Dis Care 3:129.

13. Allen SW, Whitfield JM, Clarke DR, et al. Pulmonary arteriovenous malformation in the newborn: a familial case. Pediatr Cardiol | 993;| 4:58-61.

14. Lacombe P, Lacout A, Marcy P-Y, et al. Diagnosis and treatment of pulmonary arteriovenous malformations in hereditary hemorrhagic telangiectasia: An overview. Diagnostic and Interventional Imaging 2013;94:835-848.

15. White RI, Jr, Pollak JS, Wirth JA. Pulmonary arteriovenous malformations: Diagnosis and transcatheter embolotherapy. J Vasc Interv Radiol 1996;7: 787-804. I0.1016/SI051-0443(96)7085|-5. 